\title{
Effect of Rubberized Bitumen Blending Methods on Permanent Deformation of SMA Rubberized Asphalt Mixtures
}

\author{
Herda Yati Katman, ${ }^{1,2}$ Mohd Rasdan Ibrahim, ${ }^{1}$ Mohamed Rehan Karim, ${ }^{1}$ \\ Suhana Koting, ${ }^{1}$ and Nuha Salim Mashaan ${ }^{1}$ \\ ${ }^{1}$ Centre for Transportation Engineering, Department of Civil Engineering, University of Malaya, 50603 Kuala Lumpur, Malaysia \\ ${ }^{2}$ College of Engineering, Universiti Tenaga Nasional, Putrajaya Campus, Jalan IKRAM-UNITEN, 43000 Kajang, Selangor, Malaysia
}

Correspondence should be addressed to Herda Yati Katman; herda@uniten.edu.my

Received 27 April 2016; Revised 22 June 2016; Accepted 27 June 2016

Academic Editor: Gianluca Cicala

Copyright (C) 2016 Herda Yati Katman et al. This is an open access article distributed under the Creative Commons Attribution License, which permits unrestricted use, distribution, and reproduction in any medium, provided the original work is properly cited.

\begin{abstract}
This study aims at comparing the permanent deformation of Stone Mastic Asphalt (SMA) rubberized asphalt mixtures produced by the wet process. In this study, rubberized binders were prepared using two different blending methods, namely, continuous blend and terminal blend. To study the creep behaviour of control and rubberized asphalt mixtures, the dynamic creep test was performed using Universal Materials Testing Apparatus (UMATTA) at different temperatures and stress levels. Zhou three-stage creep model was utilized to evaluate the deformation characteristics of the mixtures. In all test conditions, the highest resistance to permanent deformation is showed by the rubberized mixtures produced with continuous blend binders. This study also reveals that the permanent deformation of rubberized mixtures cannot be predicted based on the characteristics of the rubberized binders.
\end{abstract}

\section{Introduction}

The use of crumb rubber in the modification of the binder has continued to evolve since its introduction in the early 1960s. The utilization of crumb rubber in asphaltic pavement has been proven to enhance the pavement performance and at the same time provided a solution to the waste tyre scenario faced around the globe.

The interaction between bitumen and rubber particles causes a change in the composite system of bitumen-rubber from two simultaneous processes: partial digestion of the rubber into the bitumen and the adsorption of the aromatic oils available in the bitumen with the polymeric chains of the rubber [1]. The absorption of aromatic oils from the bitumen into the rubber's polymer chains causes the rubber to swell and soften producing a gel-like material with higher viscosity and elasticity [2-4].

The development of an effective interaction between bitumen and rubber is mainly an experimental iterative process. Previous studies determined that the properties of rubberized binders are highly governed by the selection of rubber crumb parameters (rubber types, rubber size, and rubber contents) and blending parameters (blending temperature, blending duration, and blending rate) $[5,6]$. Modification of these parameters will affect the rubberized binder properties and imposes on the performance of the rubberized asphalt mixtures. Thus, an optimum combination of parameters, especially the blending parameters, is important to produce high performance rubberized binder.

The preparation of rubberized binder can be divided into two broad categories: continuous blend and terminal blend method. Continuous blend is a conventional method where rubberized binder is prepared at a temperature between $160^{\circ} \mathrm{C}$ and $180^{\circ} \mathrm{C}$ for duration of $30-60$ minutes. The benefits offered by the continuous blend include improved viscosity, elasticity, and permanent deformation [7-10]. However, rubberized binders prepared using the continuous blend also have limitations, including phase separation during storage since the rubber particles are not fully digested into the bitumen. On the other hand, in the terminal blend method, crumb rubber is blended with bitumen at high shear stress (up to $8000 \mathrm{rpm}$ ) and maintained at high processing 
temperature $\left(200-260^{\circ} \mathrm{C}\right)$ for a long mixing duration $(>2$ hours). The extreme blending parameters cause the crumb rubber depolymerisation and dispersion into the bitumen, thus producing more homogenous rubberized binder compared to the continuous blend. Previous studies found that the terminal blend method improves compatibility (storage stability) of the rubberized binder [11]. The compatibility during storage can be maintained with low temperature and does not require constant agitation to keep discrete crumb rubber particles uniformly distributed in the hot bitumen. Hence, the terminal binder production cost can be minimized.

Figure 1 shows a schematic diagram explaining the relationship between the accumulated permanent deformations and the loading cycles in the dynamic creep tests using the Universal Materials Testing Apparatus (UMATTA). The figure shows that the accumulated permanent strain curve is divided into three main stages: primary, secondary, and tertiary. The derived curves are used to compare the resistance of different asphalt mixtures against permanent deformations and rutting distress. For this purpose, it is necessary to use a prediction model that not only fits the curve, but is also able to be used to identify the locations of the boundary points connecting the primary to the secondary stages and the secondary to the tertiary stages. Moreover, the prediction model should realistically characterize the different asphalt mixtures.

The Zhou model has been used by current studies to evaluate the permanent deformation of asphalt mixtures [1215]. The model can be used to develop mathematical functions to characterize the three-stage permanent deformation behaviour of asphalt mixtures and can also be used to identify the transition point between stages. Moreover, the Zhou model is comparable to the field performance. The Zhou models are presented as below:

Primary stage is as follows:

$$
\varepsilon_{p}=a N^{b}, \quad N<N_{\mathrm{PS}} .
$$

Secondary stage is as follows:

$$
\begin{aligned}
\varepsilon_{p} & =\varepsilon_{\mathrm{PS}}+c\left(N-N_{\mathrm{PS}}\right), \\
\varepsilon_{\mathrm{PS}} & =a N_{\mathrm{PS}}^{b}, \\
& N_{\mathrm{PS}} \leq N \leq N_{\mathrm{ST}} .
\end{aligned}
$$

Tertiary stage is as follows:

$$
\begin{aligned}
\varepsilon_{p} & =\varepsilon_{\mathrm{ST}}+d\left(e^{f\left(N-N_{\mathrm{ST}}\right)}-1\right), \\
\varepsilon_{\mathrm{ST}} & =\varepsilon_{\mathrm{PS}}+c\left(N_{\mathrm{ST}}-N_{\mathrm{PS}}\right),
\end{aligned}
$$

$$
N \geq N_{\text {ST }}
$$

\section{Objectives and Experimental Procedure}

Different blending methods definitely will produce rubberized binder with different rheology properties and thus results in different asphalt mixture's performance including the rutting resistance. Therefore, this study was conducted

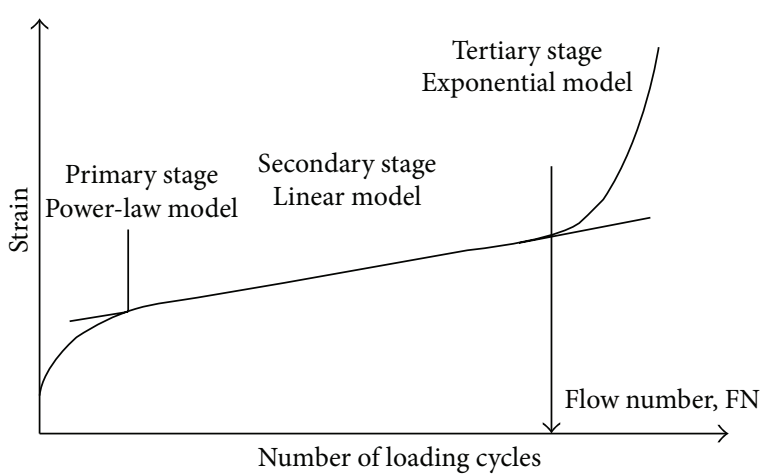

FIGURE 1: Cumulative permanent strain versus number of loading cycles [25].

to evaluate the permanent deformation of SMA mixtures containing rubberized binder prepared through continuous and terminal blend method. The permanent deformation was carried out using dynamic creep test performed by the Universal Materials Testing Apparatus (UMATTA). The test was conducted at different temperatures and stress levels. Consequently, dynamic creep curve for rubberized binder mixtures was compared and analysed to that of control mixtures. Finally, Zhou three-stage models were derived and confirmed the test results. Besides, characteristics of rubberized binder were evaluated based on penetration test, ring and ball softening point test, and viscosity test (Brookfield viscometer). The characteristics of rubberized binders were then compared to permanent deformation parameters of SMA mixtures. For each test conducted in this study, four duplicate specimens were prepared and tested. The results are shown as the average of four replicates.

2.1. Aggregate. Crushed granite aggregate was blended to meet the Malaysian Public Works Department SMA 20 gradation [16]. Aggregate was supplied from Kajang Rock Quarry in Malaysia. Table 1 shows the properties of aggregates utilized in this research. Aggregate particle size distribution is presented in Figure 2.

2.2. Bitumen. Bitumen grade $80 / 100$ penetration collected from the vacuum distillation residue obtained from crude oil is widely used in Malaysian road construction. In this study, bitumen 80/100 was obtained from Asphalt Technology Sdn. Bhd. located at Port Klang, Malaysia. Table 2 shows specifications of the bitumen $80 / 100$ penetration employed in this study.

2.3. Rubber Crumb. Rubber crumb obtained through the ambient process was used to produce rubberized binders for this research. Rubber crumb sized $0.4 \mathrm{~mm}$ ( $40 \mathrm{mesh}$ ) supplied by Rubplast Sdn. Bhd. was used for entire research. Specification of the crumb rubber is presented in Table 3.

\subsection{Sample Preparation}

2.4.1. Preparation of Rubberized Binder. Rubberized binders were produced using continuous blend and terminal blend 
TABLE 1: Properties of crushed granite aggregate used in this study.

\begin{tabular}{lccc}
\hline Property & Unit & Test method & Value \\
\hline Coarse aggregate & & & \\
Los Angeles abrasion & $\%$ & ASTM: C131 & 19.45 \\
Flakiness index & $\%$ & BS EN 933-3 & 2.72 \\
Elongation index & $\%$ & BS 812-105.2 & 11.26 \\
Aggregate crushing value & $\%$ & BS 812-110 & 19.10 \\
Bulk specific gravity & - & ASTM: C127 & 2.60 \\
Absorption & $\%$ & ASTM: C127 & \\
\hline Fine aggregate & & & \\
Bulk specific gravity & - & ASTM: C128 & \\
Absorption & $\%$ & ASTM: C128 & 2.63 \\
Soundness loss & $\%$ & ASTM: C88 & 0.4 \\
\hline
\end{tabular}

TABLE 2: Specification of bitumen $80 / 100$ penetration used in this study.

\begin{tabular}{|c|c|c|c|c|}
\hline \multirow{2}{*}{ Property } & \multirow{2}{*}{ Unit } & \multirow{2}{*}{ Test method } & \multicolumn{2}{|c|}{ Value } \\
\hline & & & Min. & Max. \\
\hline Penetration at $25^{\circ} \mathrm{C}$ & $0.1 \mathrm{~mm}$ & ASTM D5 & 80 & 100 \\
\hline Softening point (ring \& ball) & ${ }^{\circ} \mathrm{C}$ & ASTM D36 & 45 & 52 \\
\hline Flash point (Cleveland open cup) & ${ }^{\circ} \mathrm{C}$ & ASTM D92 & 225 & - \\
\hline Relative density at $25^{\circ} \mathrm{C}$ & $\mathrm{g} / \mathrm{cm}^{3}$ & ASTM D71 & 1.00 & 1.05 \\
\hline Ductility at $25^{\circ} \mathrm{C}$ & $\mathrm{cm}$ & ASTM D113 & 100 & - \\
\hline Loss on heating, wt. & $\%$. & ASTM D6 & - & 0.5 \\
\hline Solubility in trichloroethylene, wt., min. & $\%$ & ASTM D2042 & 99 & - \\
\hline Drop in penetration after heating, max. & $\%$ & ASTM D5 & - & 20 \\
\hline Application temperatures, mixing & ${ }^{\circ} \mathrm{C}$ & - & 140 & 165 \\
\hline
\end{tabular}

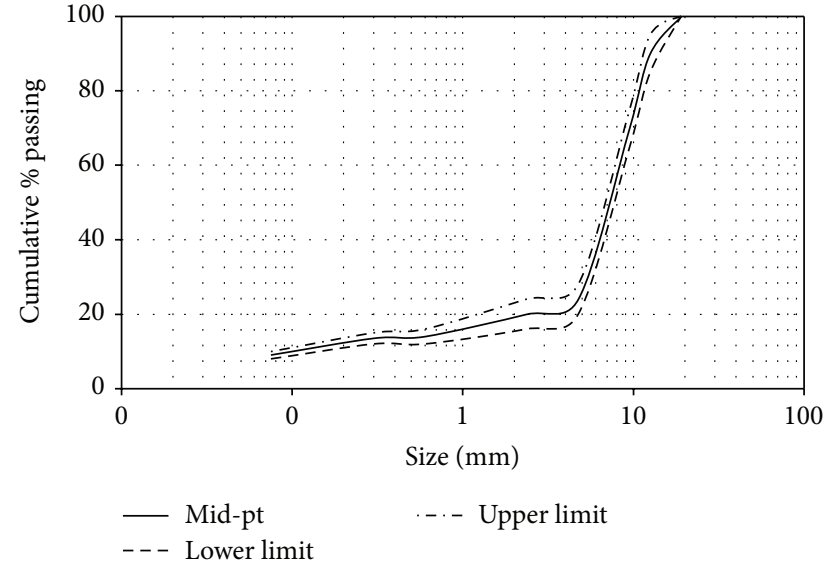

FIGURE 2: SMA 20 aggregate gradation.

method. Crumb rubbers sized $0.4 \mathrm{~mm}$ were utilized for both blending methods. Bitumen 80/100 penetration was used as base bitumen to produce the rubberized binders. The rubberized binders prepared by continuous blend were blended using Eurostar propeller mixer at speed of $200 \mathrm{rpm}$ and mixing temperature was maintained at $180^{\circ} \mathrm{C}$ for 1 hour. It was produced with $12 \%$ of rubber content by weight of bitumen $80 / 100$ penetration. The amount of rubber was selected based on author previous study [17]. On the other hand, the terminal blend binder was produced with $20 \%$ rubber content by weight of bitumen $80 / 100$ penetration. To achieve terminal blend binder, mixing was performed at high temperature $\left(210^{\circ} \mathrm{C}\right)$ for 2 hours using Silverson L4R high shear mixer at speed 10,000 rpm. Table 4 presents the designations and the features of each binder. Besides, characteristics of binders are presented in Table 5 .

2.4.2. Preparation of Asphalt Mixture Specimen. In this study, aggregate gradation SMA 20 in accordance with the Malaysian Public Works Department was used in preparation of all asphalt mixtures [18]. Aggregate particle size distribution is presented in Figure 2. SMA mixtures have been prepared with $1100 \mathrm{~g}$ of aggregates including $2 \%$ of Portland cement. According to Standard Specification for Road Works of Malaysia Public Works Department (JKR/SPJ/2008-S4) [18], mineral filler should be added as part of the combined aggregate gradation. Limestone dust, hydrated lime, or ordinary Portland cement shall be used as filler. If cement is used, the amount should not exceed $2 \%$ by weight of the combined aggregates.

Preparation of the specimen was started by heating the aggregate and cement in the oven for one hour at $160^{\circ} \mathrm{C}$. Aggregate was then transferred to the pan and heated at higher temperatures of $180^{\circ} \mathrm{C}$. Besides, rubberized binder was heated at $180^{\circ} \mathrm{C}$ before mixing with aggregate particles to achieve the proper viscosity. In order to manufacture a 
TABLE 3: Specification of crumb rubber used in this study.

\begin{tabular}{lccc}
\hline Property & Unit & Test method & Value \\
\hline Acetone extract & $\%$ & ISO 1407 & $10 \pm 3$ \\
Ash content & $\%$ & ISO & $8 \pm 3$ \\
Carbon black & $\%$ & ISO 1408 & $30 \pm 5$ \\
Rubber hydrocarbon & $\%$ & RHC & $52 \pm 5$ \\
Passing & $\%$ & ASTM D5644 & $>90$ \\
Heat loss & $\%$ & ASTM D1509 & $<1$ \\
Metal content & $\%$ & ASTM D56 & $<1$ \\
Fiber content & $\%$ & ASTM D5603 & $<3$ \\
\hline
\end{tabular}

TABLE 4: Binder features.

\begin{tabular}{|c|c|c|c|c|c|c|}
\hline $\begin{array}{l}\text { Base bitumen }(80 / 100 \\
\text { penetration }) \\
\text { Binder } \\
\text { designation }\end{array}$ & $\begin{array}{c}\text { Rubber content } \\
(\%)\end{array}$ & $\begin{array}{l}\text { Blending } \\
\text { process }\end{array}$ & $\begin{array}{l}\text { Blending } \\
\text { apparatus }\end{array}$ & $\begin{array}{l}\text { Blending speed } \\
(\mathrm{rpm})\end{array}$ & $\begin{array}{c}\text { Blending } \\
\text { duration (hour) }\end{array}$ & $\begin{array}{l}\text { Blending } \\
\text { temperature } \\
\left({ }^{\circ} \mathrm{C}\right)\end{array}$ \\
\hline $\begin{array}{l}\text { Control ( } 80 / 100 \\
\text { penetration bitumen) }\end{array}$ & 0 & N/A & $\mathrm{N} / \mathrm{A}$ & N/A & N/A & N/A \\
\hline $\begin{array}{l}\text { TB (terminal blend } \\
\text { binder) }\end{array}$ & 20 & Terminal blend & $\begin{array}{l}\text { High shear } \\
\text { mixer }\end{array}$ & 10,000 & 2 & 210 \\
\hline $\begin{array}{l}\mathrm{CB} \text { (continuous blend } \\
\text { binder) }\end{array}$ & 12 & $\begin{array}{l}\text { Continuous } \\
\text { blend }\end{array}$ & Propeller mixer & 200 & 1 & 180 \\
\hline
\end{tabular}

N/A Not applicable.

TABLE 5: Characterization of the binders.

\begin{tabular}{|c|c|c|c|c|}
\hline Test & Standard & Control & TB & $\mathrm{CB}$ \\
\hline Softening point $\left({ }^{\circ} \mathrm{C}\right)$ & ASTM D36/D36M & 44.25 & 53.88 & 51.00 \\
\hline Penetration $25^{\circ} \mathrm{C}, 100 \mathrm{~g}, 5 \mathrm{~s}(0.01 \mathrm{~mm})$ & ASTM D5-97 & 95.00 & 65.67 & 67.50 \\
\hline Apparent viscosity ${ }^{\mathrm{a}}(\mathrm{mPa} \cdot \mathrm{s}), 135^{\circ} \mathrm{C}$ & ASTM D 2196-99 & 375.25 & 1277.00 & 807.80 \\
\hline Apparent viscosity ${ }^{\mathrm{a}}(\mathrm{mPa} \cdot \mathrm{s}), 175^{\circ} \mathrm{C}$ & ASTM D 2196-99 & 43.75 & 287.75 & 260.20 \\
\hline
\end{tabular}

${ }^{\mathrm{a}}$ Brookfield viscometer, spindle number 27, $20 \mathrm{rpm}$.

homogeneous binder, the rubberized binder was agitated vigorously before it was added to the aggregate. In this study, asphalt mixture was compacted by applying 50 blows for both sides with the Marshall compactor. In general, the specimens have a range of diameter and height between 101-102 mm and $65-68 \mathrm{~mm}$, respectively. All specimens were prepared at Optimum Binder Content (OBC), and the results are presented in Table 6. The Optimum Binder Content (OBC) was determined in accordance with Marshall mix design. For the determination of $\mathrm{OBC}$, four graphs, namely, stability, flow, voids in the mix (VIM), and voids in mineral aggregate (VMA), were plotted versus the percentage of binder for each asphalt mixture. OBCs were calculated based on the SMA mix requirements [18]: stability (min. $6200 \mathrm{~N})$, flow $(2-4 \mathrm{~mm})$, VIM (3-5\%), and VMA (min. 17\%). The same designations were selected in asphalt mixture specimens prepared from the respective binders.

2.4.3. Penetration Test. The penetration test was carried out according to ASTM D5 [19]. Sufficient bitumen was heated and poured in the penetration cup and conditioned at $25^{\circ} \mathrm{C}$ for 24 hours prior to testing. The test was conducted at a specified temperature of $25^{\circ} \mathrm{C}$; a water bath was used to maintain the test temperature. A $1 \mathrm{~mm}$ diameter needle was loaded with a weight of $100 \mathrm{~g}$ and allowed to penetrate freely for $5 \mathrm{~s}$ into a bitumen sample.

2.4.4. Softening Point Test. The softening point (ring and ball) test was conducted in accordance with ASTM D36 [20]. A ring holder assembly filled with binder was placed in a water bath along with two steel balls which were allowed to condition to a starting temperature of $5 \pm 1^{\circ} \mathrm{C}$ for 15 minutes. After the conditioning period, the steel balls were placed on top of the binder in the ring. The test was conducted by heating the two horizontal discs of binder immersed in a water bath at a controlled rate $\left(5^{\circ} \mathrm{C} / \mathrm{min}\right)$. The softening point value was recorded as the temperature at which the binder softens enough to allow each steel ball to fall and touch the plate.

2.4.5. Apparent Viscosity by Rotational (Brookfield Type) Viscometer. The rotational (Brookfield type) viscometer was used to measure the apparent viscosity of the binder in accordance with ASTM D2196-10 [21]. In this test, a sufficient 
TABLE 6: Summary of asphalt mixture.

\begin{tabular}{|c|c|c|c|c|c|c|}
\hline $\begin{array}{l}\text { Asphalt mixture } \\
\text { designation }\end{array}$ & Binder & Rubber content (\%) & $\mathrm{BSG}^{\mathrm{a}}$ & $\mathrm{VMA}^{\mathrm{b}}(\%)$ & $\operatorname{VIM}^{\mathrm{c}}(\%)$ & $\mathrm{OBC}^{\mathrm{d}}(\%)$ \\
\hline $\begin{array}{l}\text { Control (asphalt mixture } \\
\text { prepared with } 80 / 100 \\
\text { penetration bitumen) }\end{array}$ & $80 / 100$ pen. & 0 & 2.31 & 18.55 & 5.43 & 5.78 \\
\hline $\begin{array}{l}\text { CB (asphalt mixture } \\
\text { prepared with continuous } \\
\text { blend binder) }\end{array}$ & Continuous blend & 12 & 2.30 & 19.65 & 5.21 & 6.50 \\
\hline $\begin{array}{l}\text { TB (asphalt mixture } \\
\text { prepared with terminal } \\
\text { blend binder) }\end{array}$ & Terminal blend & 20 & 2.27 & 20.75 & 5.76 & 6.86 \\
\hline
\end{tabular}

${ }^{a}$ Bulk specific gravity of compacted mixture.

${ }^{\mathrm{b}}$ Void in mineral aggregate.

${ }^{\mathrm{c}}$ Void in mix.

${ }^{\mathrm{d}}$ Optimum Binder Content.

amount of binder was heated in an oven so that it was sufficiently fluid to pour into the sample chamber. The sample chamber containing $8-10 \mathrm{~mL}$ binder was then positioned in the thermos container. In this study, the test was conducted at $175^{\circ} \mathrm{C}$ at a fixed speed of $20 \mathrm{rpm}$.

2.5. Dynamic Creep Test. In this work the mechanical performance of the studied asphalt mixtures was evaluated through the dynamic creep test. The test was performed using Universal Materials Testing Apparatus (UMATTA). Asphalt mixtures were trimmed at top and bottom side with a diamond saw to the final thickness of $50 \mathrm{~mm}$. Both sides of each asphalt mixture were coated with a thin layer of silicone grease containing graphite flakes in order to obtain smooth faces. Asphalt mixture with a geometrical size of $50 \mathrm{~mm}$ thickness and $100 \mathrm{~mm}$ in diameter $(50 \mathrm{~mm}$ $\times 100 \mathrm{~mm}$ ) will be placed in the temperature controlled cabinet for 2 hours to ensure that equilibrium temperature is reached. Asphalt mixture was then placed between the platens and aligned concentrically with the loading axis of the testing machine. The Linear Variable Differential Transducers (LVDTs) are then attached to the platens to measure the vertical deformation during the test. The tests were conducted at three different temperatures, namely, $40^{\circ} \mathrm{C}, 50^{\circ} \mathrm{C}$, and $60^{\circ} \mathrm{C}$, to simulate high pavement temperature to which the mixtures are subjected when applied in Malaysian road. In addition, two stress levels of $200 \mathrm{kPa}$ and $400 \mathrm{kPa}$ were selected. The applied stress consisting of a haversine wave shape has a duration of $0.5 \mathrm{~s}$ followed by a rest period of $1.5 \mathrm{~s}$ which was executed to each mixture. The strain gauge load cell in UMATTA measures the deformation when the asphalt mixture deforms appropriately at the applied stress level. The test was terminated after 1800 load cycles or until the accumulated strain reaches $70,000 \mu \mathrm{s}$.

The accumulated strain was calculated by using the following equation:

$$
\varepsilon=\frac{h}{H_{0}},
$$

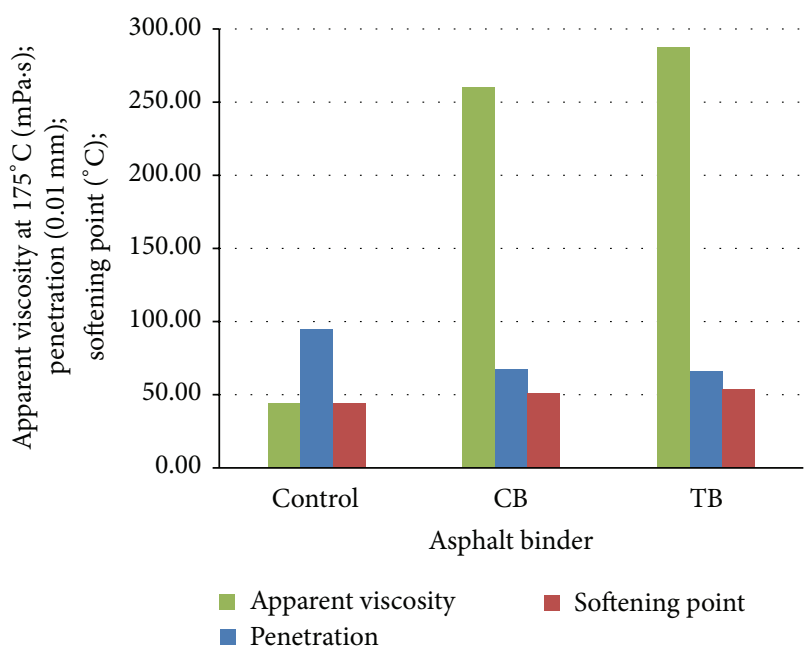

Figure 3: Characterization tests of the binders.

where $\varepsilon$ is the accumulated strain, $h$ is the axial deformation, $\mathrm{mm}$, and $H_{0}$ is the initial specimen height, $\mathrm{mm}$.

\section{Analysis and Evaluation of Results}

3.1. Characterization of Binders. The binders were characterized by apparent viscosity test, penetration test, and softening point (ring and ball test). The results of the binder characterization can be seen in Table 5 and Figure 3. As expected, both rubberized binders prepared by terminal blend and continuous blend showed higher softening point, apparent viscosity, and lower penetration value compared to control (bitumen $80 / 100$ penetration). This confirmed previous studies that incorporating rubber crumb to base bitumen results in higher viscosity and elasticity $[6,11,22]$. It is important to note that the rubberized binder produced by the terminal blend (TB) showed higher softening point and apparent viscosity followed by a continuous blend binder (CB) and control. Moreover, penetration value for TB is the lowest, followed by $\mathrm{CB}$ and control. These results can be 
explained by the amount of rubber crumb, where TB was prepared with higher rubber content compared to $\mathrm{CB}$ (TB: $20 \%$, CB: $12 \%)$. From the above findings, the study concluded that the most viscous binder was achieved by TB.

3.2. Characteristics of Permanent Deformation. This section discusses permanent deformation performance of control mixture (unmodified) and rubberized mixtures (TB and CB). Different stages of the creep curve (primary, secondary, and tertiary stage) may develop after applying a load to the asphalt mixture. The power law, a linear function, and an exponential model were used to characterize the primary, secondary, and tertiary stage, respectively.

3.2.1. Permanent Strain. Total permanent strain of control and rubberized mixtures was calculated and compared with each other. The results are shown in Figures 4(a)-4(f). As can be seen in these figures, the control mixture presents the highest permanent strain and, therefore, the lowest resistance to permanent deformation, while the rutting resistance of rubberized mixtures improved remarkably compared to control mixtures. Above results can be explained by the roles of crumb rubber which increases the viscosity and stiffness of the binder that contributes in the formation of a thicker coating of binder mastics around the coarse aggregates. This reduces aggregate shear sliding at the interface as well as the flow of asphalt mixture and thus contributes to higher resistance to permanent deformation.

In all cases, the obtained results indicate that mixtures prepared with a continuous blend binder present the best rutting resistance followed by the terminal blend and control (rutting resistance $\mathrm{CB}>\mathrm{TB}>$ control). The terminal blend mixture was prepared with a high viscous binder; nevertheless, it shows less rutting resistance compared to the continuous blend mixtures. This can be explained by the processing conditions used in the terminal blend binder. The high mixing temperature $\left(210^{\circ} \mathrm{C}\right)$ and high shear stress $(10,000 \mathrm{rpm})$ together with the long mixing duration (2 hours) used in the preparation of the terminal blend binder lead to depolymerisation/devulcanisation of the rubber network. Depolymerisation starts releasing rubber components back to the liquid phase causing a decrease in the stiffness, and a further increase in the mixing temperature and mixing duration leads to the failure stage in which the rubberized binder loses its elastic properties [23, 24].

3.3. Temperature and Stress Level. Figures 5(a) and 5(b) show that incorporating a rubberized binder to mixtures decreases the temperature susceptibility. At all test temperatures, rubberized asphalt mixtures present the lowest cumulative permanent strain. This indicates that the dependency of permanent deformation on temperature in rubberized asphalt mixtures is considerably lower than that of control mixture. For example, the final amount of accumulated strain at $40^{\circ} \mathrm{C}$ and $200 \mathrm{kPa}$ stress for control asphalt mixture is $21901.063 \mu \mathrm{s}$, while $\mathrm{TB}$ and $\mathrm{CB}$ asphalt mixtures obtain $15324.824 \mu \mathrm{s}$ and $14337.222 \mu \mathrm{s}$, respectively, at the same test condition, approximately 1.5 times lower in comparison with control asphalt mixture.
As expected, total permanent strain for all asphalt mixtures increases at higher temperature. For instance, at $400 \mathrm{kPa}$ stress level when temperature increases from $40^{\circ} \mathrm{C}$ to $50^{\circ} \mathrm{C}$, the strain value rises $2.20,1.61$, and 1.38 times for control asphalt mixture, $\mathrm{TB}$, and $\mathrm{CB}$, respectively. It is good to note that at both temperatures $\left(40^{\circ} \mathrm{C}\right.$ and $\left.50^{\circ} \mathrm{C}\right)$ all asphalt mixtures reach the secondary stage. Moreover, further increase in temperature from $50^{\circ} \mathrm{C}$ to $60^{\circ} \mathrm{C}$ causes higher cumulative permanent strain. As can be seen in Figures 5(a) and 5(b), all asphalt mixtures enter its tertiary stage as temperature increases to $60^{\circ} \mathrm{C}$. The results show that the control asphalt mixture enters the tertiary stage earlier followed by $\mathrm{TB}$ and $\mathrm{CB}$. Furthermore, at high temperature $\left(60^{\circ} \mathrm{C}\right)$, all asphalt mixtures reach to $70,000 \mu$ s after applying a number of load cycles in which the LVDTs go out of range. A similar trend was observed at $200 \mathrm{kPa}$ stress level, where permanent strain increases at higher temperature.

The test results also determine that the strain values increase by an increment in stress levels (from $200 \mathrm{kPa}$ to $400 \mathrm{kPa}$ ) for all test temperatures. For instance, the increase in stress level from $200 \mathrm{kPa}$ to $400 \mathrm{kPa}$ at $50^{\circ} \mathrm{C}$ results in control mixture entering the tertiary stage. Moreover, at $60^{\circ} \mathrm{C}$, the increase in stress level from $200 \mathrm{kPa}$ to $400 \mathrm{kPa}$ indicates that all the mixtures reach the tertiary stage faster. Furthermore, the number of cycles where LVDTs go out of range is shorter at $400 \mathrm{kPa}$ compared to the $200 \mathrm{kPa}$ stress level. For instance, at $200 \mathrm{kPa}$ and $60^{\circ} \mathrm{C}$ temperature, the number of cycles where the LVDTs go out of range is 973 and 1249 cycles for control and TB, respectively. A further increase in stress level from $200 \mathrm{kPa}$ to $400 \mathrm{kPa}$ at $60^{\circ} \mathrm{C}$ temperature shows that the number of cycles that makes the LVDTs go out of range reduces by around one-third to one-fourth, that is, 313,339 , and 482 cycles for control, TB, and CB, respectively.

Interesting findings were observed by $\mathrm{TB}$ and $\mathrm{CB}$ at low temperature for both stress levels $(200 \mathrm{kPa}$ and $400 \mathrm{kPa})$. As illustrated in Figures 5(a) and 5(b), TB and CB show similar performance at $40^{\circ} \mathrm{C}$ temperature. For instance, at $200 \mathrm{kPa}$ and $40^{\circ} \mathrm{C}$ temperature, $\mathrm{TB}$ reaches maximum strain of $15324.824 \mu$ s, while $\mathrm{CB}$ obtains $14337.22 \mu$ s which results in small difference, $6.4 \%$ only. Moreover, at $200 \mathrm{kPa}$ stress level, rubberized asphalt mixtures tested at high temperature outperform the control asphalt mixture tested at low temperature. It can be seen in Figure 5(a) that the $\mathrm{CB}$ and TB tested at $50^{\circ} \mathrm{C}$ and $200 \mathrm{kPa}$ stress level show similar cumulative permanent strain with a control asphalt mixture tested at $40^{\circ} \mathrm{C}$ and $200 \mathrm{kPa}$ stress level. Again, these findings show that rubberized asphalt mixtures are less susceptible to temperature compared to unmodified mixture.

3.4. Zhou's Three-Stage Model. In this study, mathematical models termed Zhou's three-stage model was used to further evaluate the permanent deformation of asphalt mixtures. Zhou's model proposed different mathematical model for primary, secondary, and tertiary stages with a simple algorithm for estimating the end point of each stage. Moreover, other permanent deformation parameters such as slope of linear part, end point at the first stage, and flow number (FN) also can be determined. Regression analysis by Microsoft Excel was utilized for modelling each stage in order to find the 


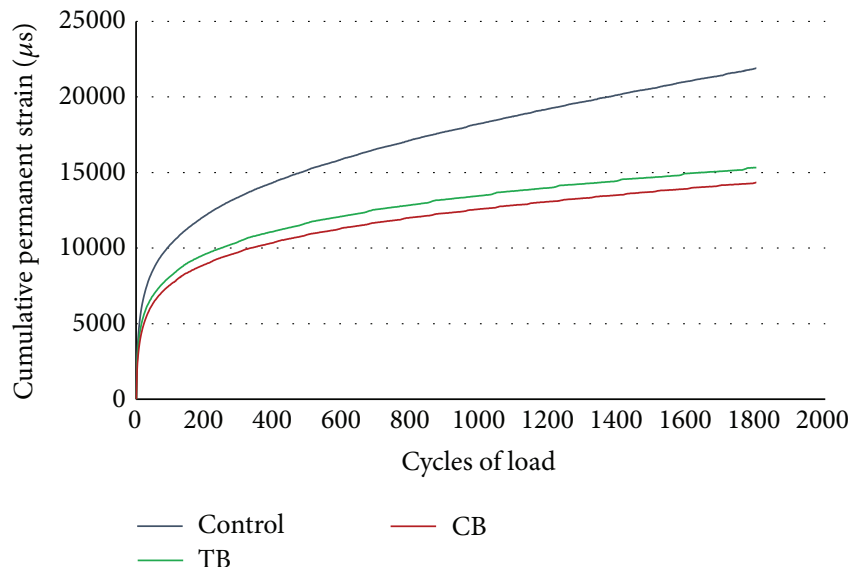

(a)

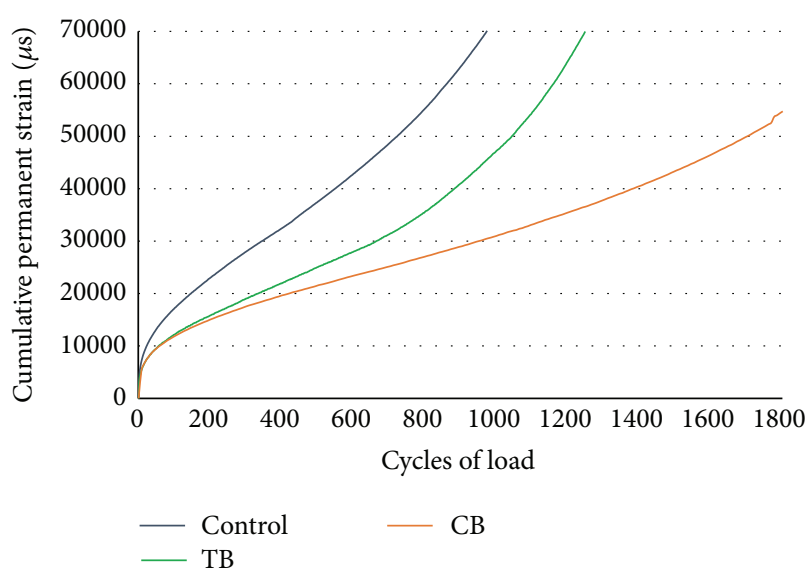

(c)

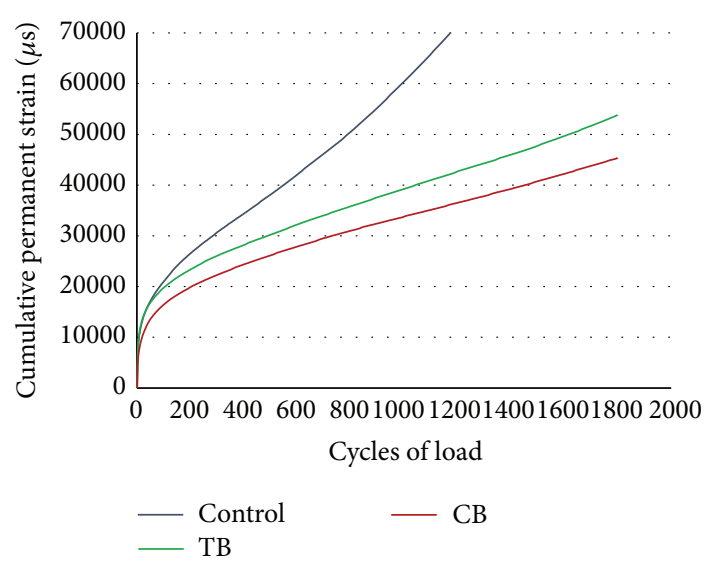

(e)
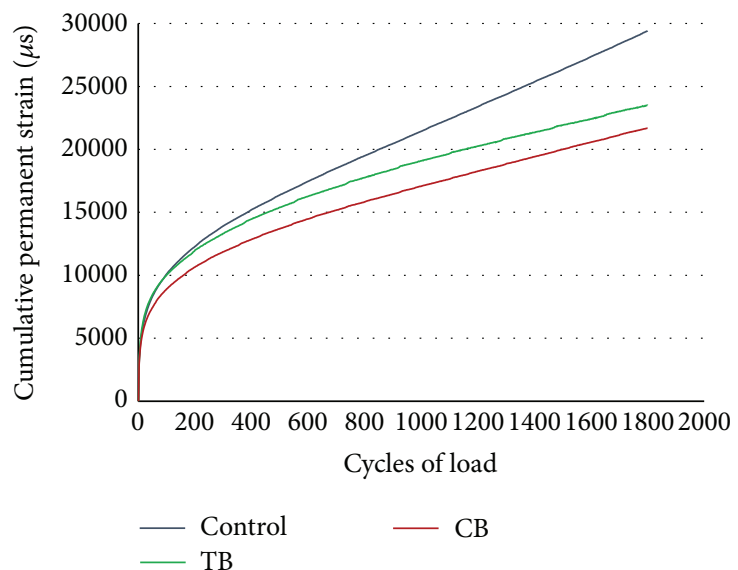

(b)

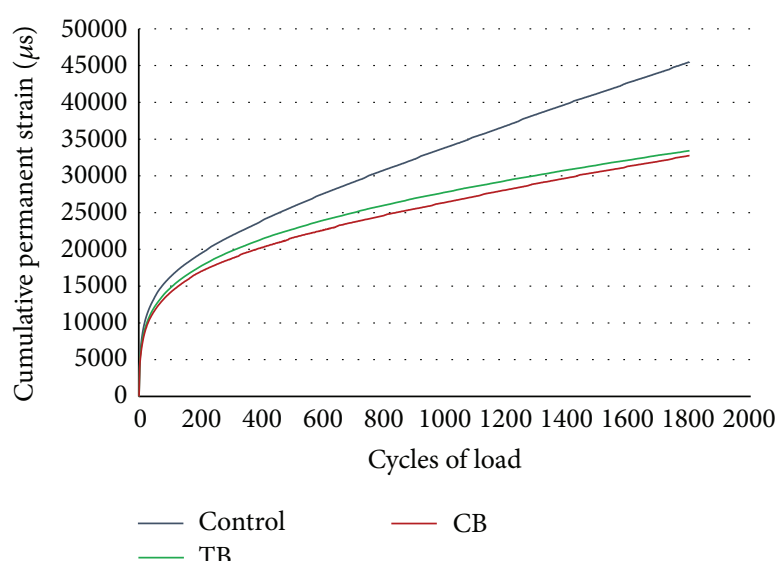

(d)

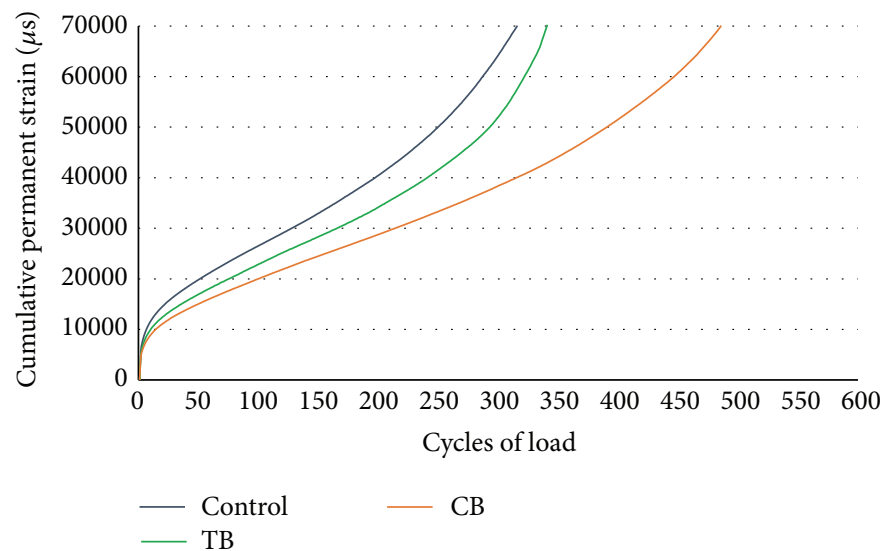

(f)

Figure 4: (a) Cumulative permanent strain versus load cycle for control and rubberized asphalt mixtures tested at $200 \mathrm{kPa}$ at $40^{\circ} \mathrm{C}$. (b) Cumulative permanent strain versus load cycle for control and rubberized asphalt mixtures tested at $200 \mathrm{kPa}$ at $50^{\circ} \mathrm{C}$. (c) Cumulative permanent strain versus load cycle for control and rubberized asphalt mixtures tested at $200 \mathrm{kPa}$ at $60^{\circ} \mathrm{C}$. (d) Cumulative permanent strain versus load cycle for control and rubberized asphalt mixtures tested at $400 \mathrm{kPa}$ at $40^{\circ} \mathrm{C}$. (e) Cumulative permanent strain versus load cycle for control and rubberized asphalt mixtures tested at $400 \mathrm{kPa}$ at $50^{\circ} \mathrm{C}$. (f) Cumulative permanent strain versus load cycle for control and rubberized asphalt mixtures tested at $400 \mathrm{kPa}$ at $60^{\circ} \mathrm{C}$. 


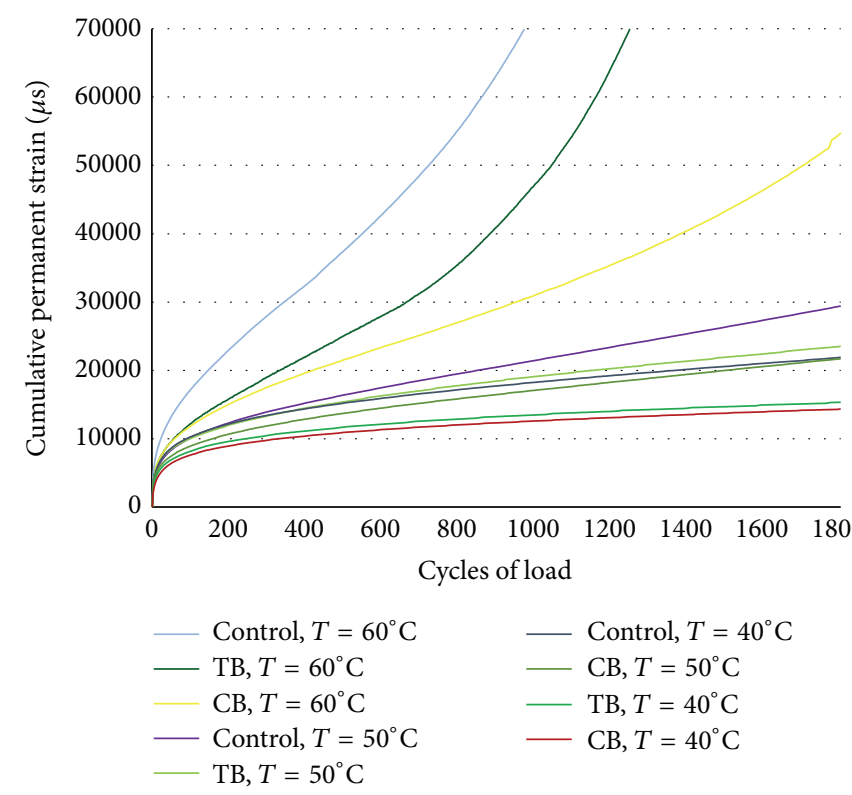

(a)

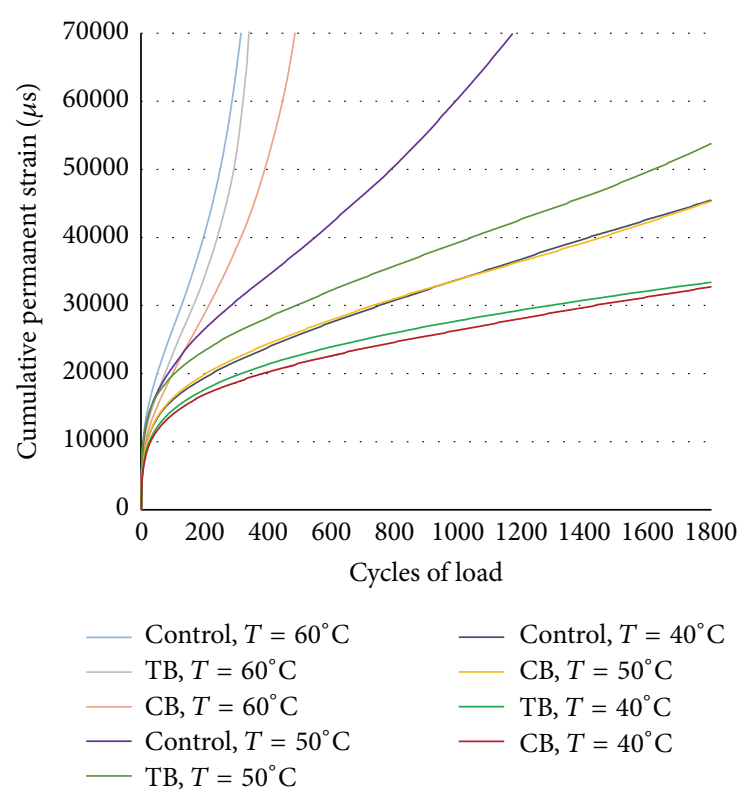

(b)

FIGURE 5: (a) Creep curve for control and rubberized asphalt mixtures at different temperatures tested at $200 \mathrm{kPa}$. (b) Creep curve for control and rubberized asphalt mixtures at different temperatures tested at $400 \mathrm{kPa}$.

parameters as well as end points between each stage. The mathematical models, the end points, and other parameters for each stage are presented in Tables 7 and 8.

3.4.1. Effects of Temperature and Stress Levels. Zhou's models confirm the importance of the temperature and stress level on the permanent deformation of the asphalt mixtures. As seen in Tables 7 and 8, none of the mixture went through the tertiary stage at low temperature $\left(40^{\circ} \mathrm{C}\right.$ and $\left.50^{\circ} \mathrm{C}\right)$. However, with an increase of $10^{\circ} \mathrm{C}$, from $50^{\circ} \mathrm{C}$ to $60^{\circ} \mathrm{C}$, it seems that all the stages are presented. Zhou's models also determined that an increase in stress levels leads to an increase in permanent deformation, as shown by the control asphalt mixture tested at $50^{\circ} \mathrm{C}$ temperature for stress levels of $200 \mathrm{kPa}$ and $400 \mathrm{kPa}$. The attained result shows that the control asphalt mixture tested at $50^{\circ} \mathrm{C}$ and $200 \mathrm{kPa}$ stress level enters the secondary stage at 479 cycles and did not reach its tertiary stage until the end of the test. A further increase in stress level (from $200 \mathrm{kPa}$ to $400 \mathrm{kPa}$ ) demonstrates that the control asphalt mixture enters the secondary stage at lower cycle (169 cycles) and reaches its tertiary stage at 829 load cycles.

3.4.2. Predicted Strain versus Measured Strain. The mathematical model at each stage predicts precisely the strain value for the control and rubberized asphalt mixtures. For instance, in case of the control asphalt mixture at $200 \mathrm{kPa}$ and temperature of $60^{\circ} \mathrm{C}$, the models predict the strains $21429.6 \mu \mathrm{s}$ and $50260.5 \mu \mathrm{s}$ for the end point primary and end point secondary stages, respectively, which are comparable values to the measured strain, that is, $21786.8 \mu \mathrm{s}$ and $51394.7 \mu \mathrm{s}$ for similar end points. In general, for all asphalt mixtures, the predicted strain values calculated from the model are similar to the measured strain values obtained from the dynamic creep test, as can be seen in Tables 7 and 8 .

3.4.3. End Point at First Stage of Asphalt Mixture. Figures 6(a) and 6(b) present the end point at first stage of creep curve for $200 \mathrm{kPa}$ and $400 \mathrm{kPa}$ stress levels. The end point for the first stage is known as the transition point from the first stage to the second stage for all mixtures. It indicates the initial axial strain of the mixtures, which reflects the permanent deformation in the densification stage. The higher the end point for the first stage, the larger the initial permanent deformation.

Figure 6(a) shows the end point at the first stage of the creep curve carried out at $200 \mathrm{kPa}$ stress level. As seen from the figure, different patterns are observed for each test condition. Therefore, it is difficult to conclude the effect of rubber and blending type on the rutting resistance based on the end point for the first stage. These observations suggest that initial permanent deformation cannot be used to evaluate the rutting resistance of rubberized mixtures.

The results determine that the stress level of $200 \mathrm{kPa}$ is not enough to show the densification behaviour of rubberized mixtures. This finding is comparable to a study conducted by Khodaii and Mehrara [12]. In their research, they found that low stress level $(100 \mathrm{kPa})$ is not sufficiently high enough for evaluation of permanent deformation behaviour of StyreneButadiene-Styrene (SBS) modified asphalt mixtures. They also mentioned that, by applying $100 \mathrm{kPa}$ for a certain number of loading cycles, SBS modified asphalt mixtures approach elastic state and result in creep curve that does not comply with the Zhou model trend. On the contrary, Baghaee Moghaddam et al. [25] applied high stress level $(300 \mathrm{kPa}$ and $400 \mathrm{kPa}$ ) to Polyethylene Terephthalate (PET) modified 


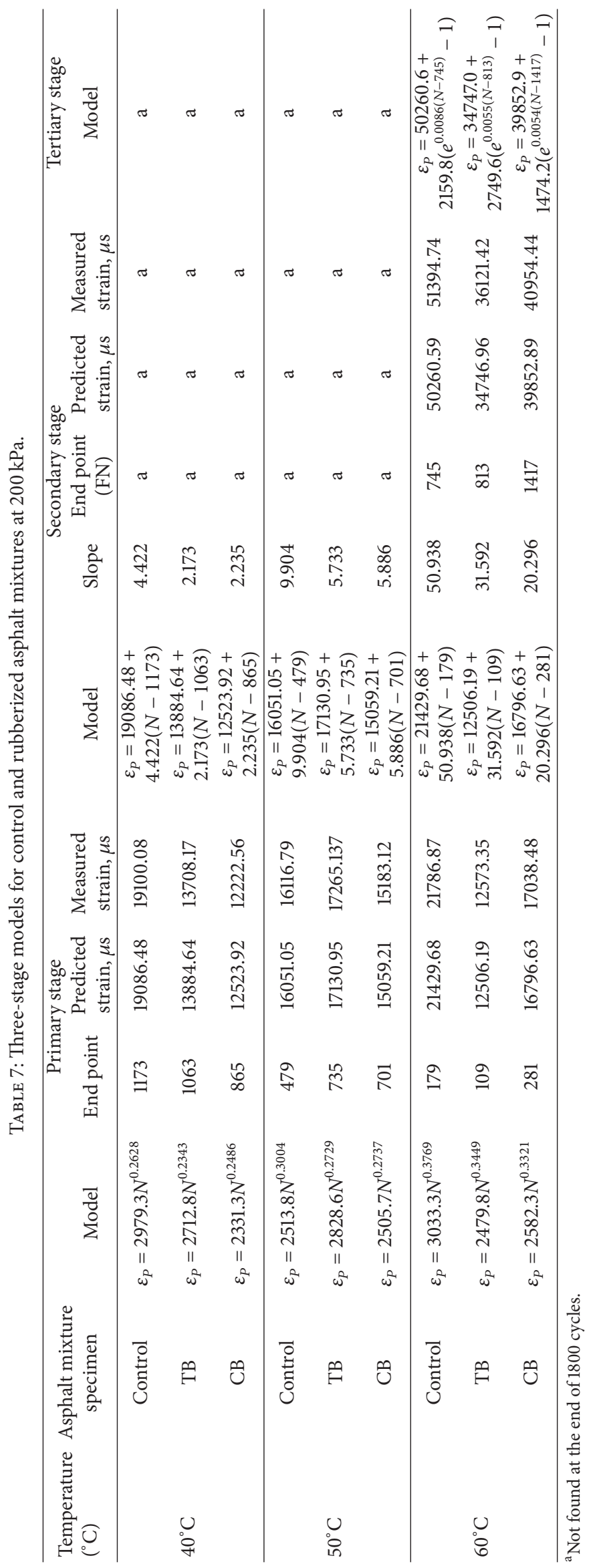




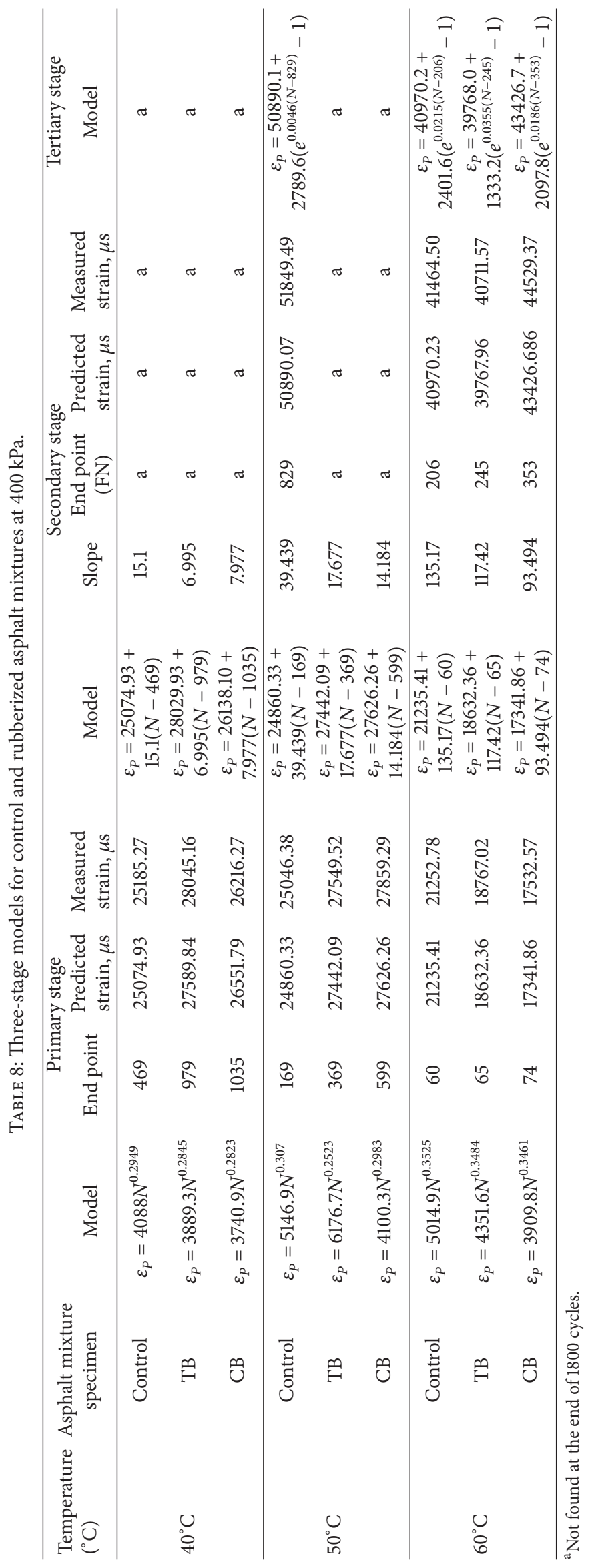




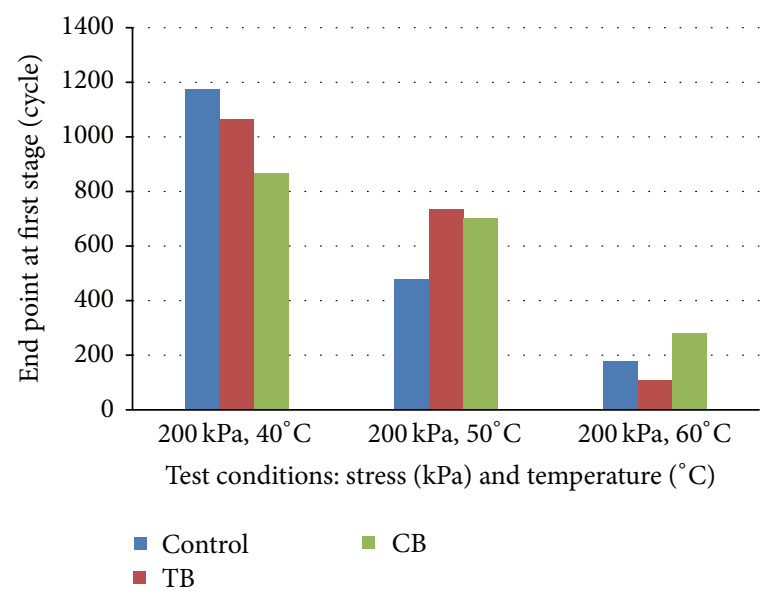

(a)

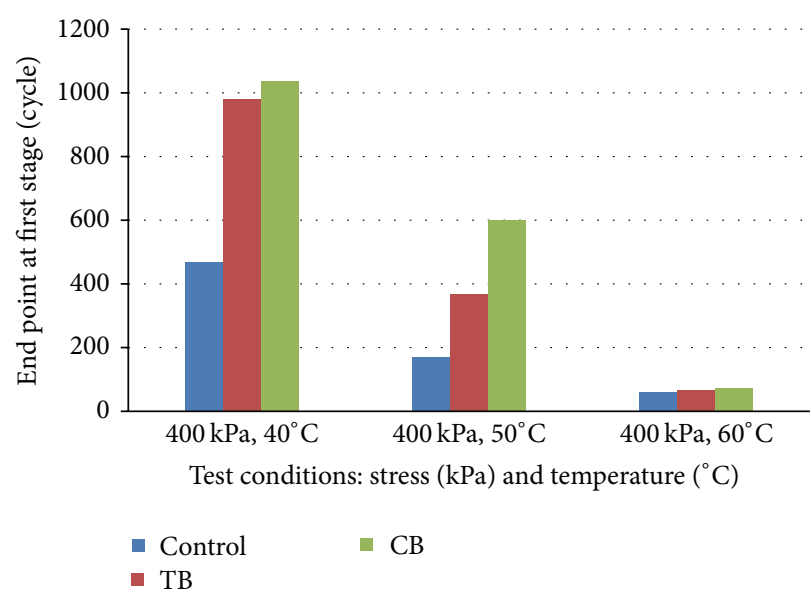

(b)

FIGURE 6: (a) End point at first stage for control and rubberized asphalt mixtures at different temperatures tested at $200 \mathrm{kPa}$. (b) End point at first stage for control and rubberized asphalt mixtures at different temperatures tested at $400 \mathrm{kPa}$.

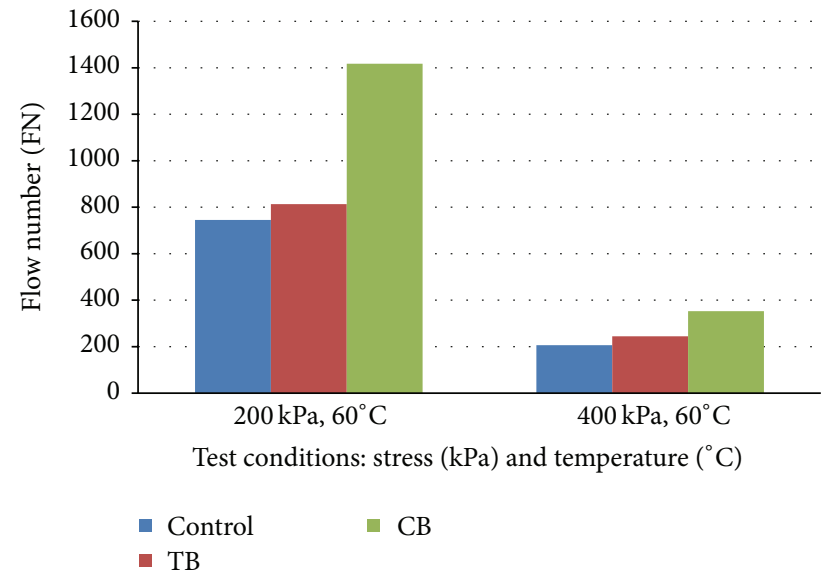

FIGURE 7: Flow number (FN) for control and rubberized asphalt mixtures at different stress levels tested at $60^{\circ} \mathrm{C}$.

asphalt mixtures and found that effect of PET modifications was more apparent at high stress level $(400 \mathrm{kPa})$.

Moreover, the end point at first stage shows the length of first stage before entering its second stage. Effects of binder blend to the length of the first stage can be seen in Figure 6(b). From this figure, at $400 \mathrm{kPa}$ stress level, it can be illustrated that $\mathrm{CB}$ asphalt mixture presents the longest primary stage followed by TB and control asphalt mixtures at all test temperatures. It is important to note that the effect of binder blends can be more highlighted at low temperature $\left(40^{\circ} \mathrm{C}\right.$ and $\left.50^{\circ} \mathrm{C}\right)$, while, at high temperature $\left(60^{\circ} \mathrm{C}\right)$, the end point at the first stage is almost similar for all asphalt mixtures.

3.4.4. Flow Number (FN). Figure 7 shows the FN value at $60^{\circ} \mathrm{C}$ temperature for both stress levels $200 \mathrm{kPa}$ and $400 \mathrm{kPa}$. $\mathrm{FN}$ is also recognized as end point at secondary stage. As can be seen in Figure 7, FN increases considerably when utilizing rubberized binder in the asphalt mixture. This figure illustrates that rubberized asphalt mixtures show a longer stage (total primary and secondary stages) compared to the control asphalt mixture before entering the tertiary stage. For instance, CB and TB show 1.9 and 1.09 times longer compared to the control asphalt mixture. Again, the FN value shows that the stress levels affect the resistance to permanent deformation as all mixtures enter the tertiary stage faster at $400 \mathrm{kPa}$ compared to $200 \mathrm{kPa}$.

3.4.5. Slope of Secondary Stage. Figures 8(a) and 8(b) show the slope of the secondary stage. For constant stress loading conditions, the strain rate is approximately constant during the secondary stage. Therefore, slope at secondary stage is a significant factor that shows the developing rate of deformation.

At both temperatures $\left(40^{\circ} \mathrm{C}\right.$ and $\left.50^{\circ} \mathrm{C}\right)$ for both stress levels $(200 \mathrm{kPa}$ and $400 \mathrm{kPa}$ ), Figures $8(\mathrm{a})$ and $8(\mathrm{~b})$ illustrate that the slope of the control asphalt mixture is the highest, while $\mathrm{TB}$ and $\mathrm{CB}$ asphalt mixtures show comparable slope value. However, at high temperature $\left(60^{\circ} \mathrm{C}\right)$ at both $200 \mathrm{kPa}$ and $400 \mathrm{kPa}$ stress levels, the effect of the rubberized asphalt mixtures is more apparent with the highest slope being shown by the control asphalt mixture, followed by TB and CB. This indicates that the effects of binder blends are more apparent at high temperature. For instance, at $50^{\circ} \mathrm{C}$ and $200 \mathrm{kPa}$ stress level, the slope obtained for both rubberized asphalt mixtures is similar, that is, 5.733 and 5.886 for $\mathrm{CB}$ and $\mathrm{TB}$, respectively (increased 2.60\%). However, an increase of $10^{\circ} \mathrm{C}$ from $50^{\circ} \mathrm{C}$ to $60^{\circ} \mathrm{C}$ at the same stress level leads to a significant difference, that is, 20.296 and 31.592 for $\mathrm{CB}$ and $\mathrm{TB}$, respectively (increased $35.76 \%$ ). At all cases, the rubberized asphalt mixtures show lower slope compared to the control asphalt mixtures. For example, at $60^{\circ} \mathrm{C}$ and $200 \mathrm{kPa}$ stress level, the slope obtained for $\mathrm{CB}, \mathrm{TB}$, and the control is $20.296,31.592$, and 50.938 , respectively, which indicates that the slope gradients for $\mathrm{CB}$ and $\mathrm{TB}$ are 2.5 and 1.5 times lower compared to the control. 


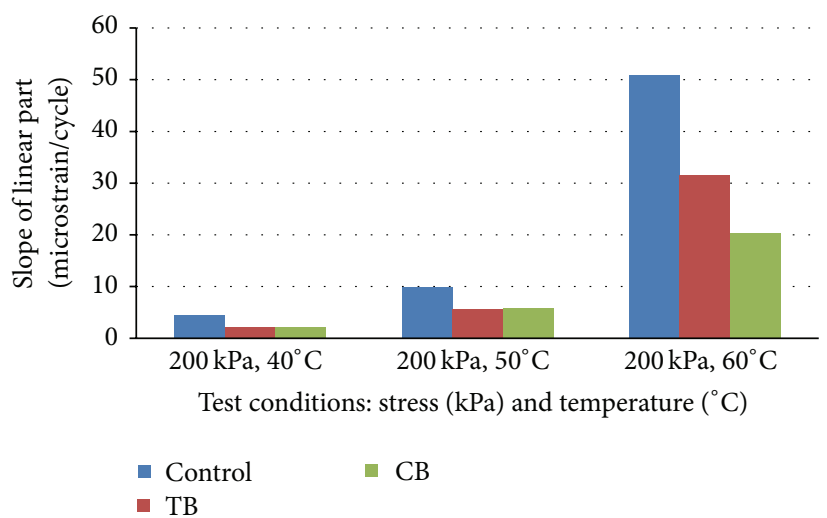

(a)

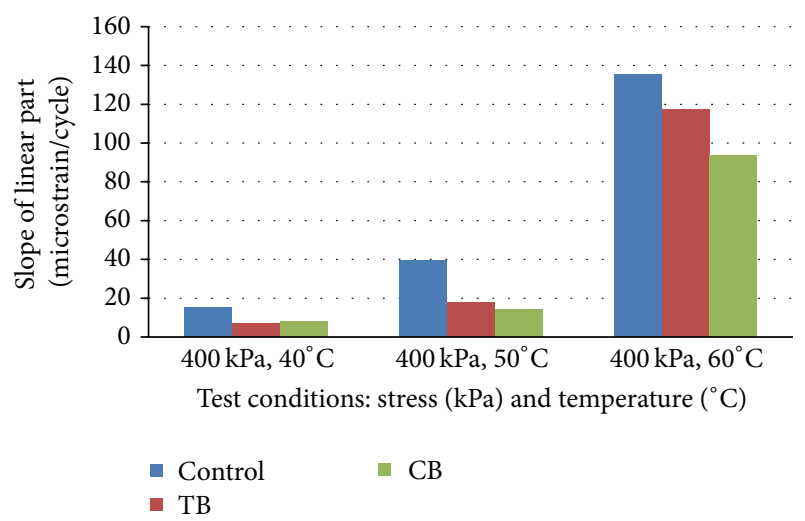

(b)

FIGURE 8: (a) Slope of secondary stage for control and rubberized asphalt mixtures at different temperatures tested at $200 \mathrm{kPa}$. (b) Slope of secondary stage for control and rubberized asphalt mixtures at different temperatures tested at $400 \mathrm{kPa}$.

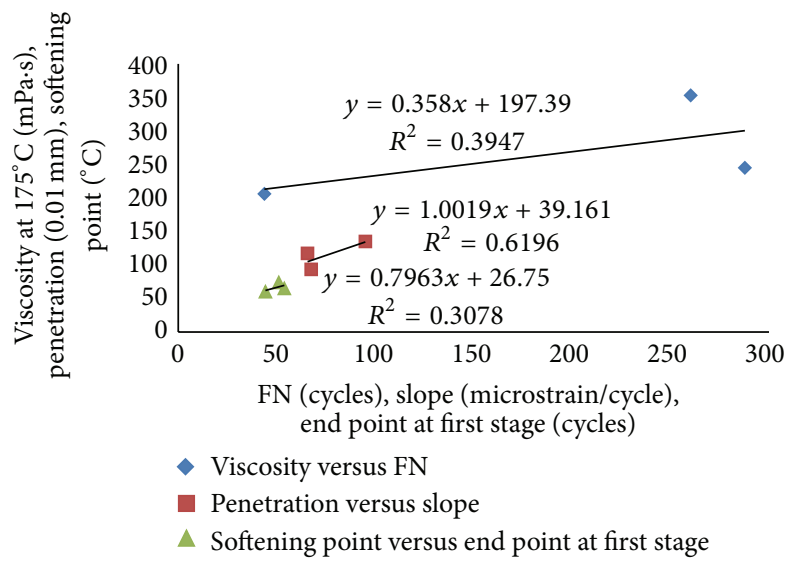

FIGURE 9: Characteristics of binders versus parameters of permanent deformation of asphalt mixtures.

3.5. Characterization of Binders versus Asphalt Mixtures. Characteristics of binder (viscosity, penetration, and softening point values) can be used as indicators of the permanent deformation resistance of asphalt mixtures. Previous studies indicated that viscous binder leads to the stiffening of the asphalt mixtures at higher temperature, thus improving the resistance to permanent deformation [9].

Figure 9 shows characteristics of binders compared to permanent deformation parameters of asphalt mixtures. Characteristics of binders are compared with a slope of secondary stage, flow number (FN), and end point at the first stage of asphalt mixtures. For example, the points of viscosity versus FN in Figure 9 was obtained by plotting the viscosity of binders (control binder, continuous blend binder, and terminal blend binder) with FN of asphalt mixtures (control asphalt mixture, continuous asphalt mixture, and terminal asphalt mixture, resp.).

Figure 9 shows that the correlation between the binder characteristics and the permanent deformation parameters of asphalt mixtures does not exist. It is shown by the low $R^{2}$ value (0.3-0.6). Similar findings observed by Blazejowski and Dolzycki (2014) and Dreessen et al. (2009) are that binder properties are not a reliable indicator of the rutting potential of the binders, especially the modified binders [26, 27]. As shown in this study, Brookfield viscometer shows that terminal blend binder (TB) provides extra viscosity than continuous blend binder (CB) as showed in Figure 3. Thus, the authors predict that TB asphalt mixtures should be more resistant to permanent deformation compared to $\mathrm{CB}$ asphalt mixtures. However, test results depict opposite findings; TB asphalt mixtures show lower resistance compared to $\mathrm{CB}$ asphalt mixtures as shown in Figures 4(a)-4(f) and Figures 5(a) and 5(b). In other words, TB asphalt mixtures were prepared using higher viscosity binder compared to $\mathrm{CB}$ asphalt mixtures; nevertheless it results in lower resistance to permanent deformation. The mixing parameters used in the preparation of terminal blend binder might be the main reason. High mixing speed $(10,000 \mathrm{rpm})$ at a high mixing temperature $\left(210^{\circ} \mathrm{C}\right)$ for long mixing duration (2 hours) causes depolymerisation/devulcanisation of the rubber network thus producing a mixture with overly stress sensitivity (low rutting resistance).

Blazejowski and Dolzycki (2014) relates low relationship of binder properties to rutting with selection of aggregate gradation [26]. Comparison study between SMA mixtures, high modulus asphalt concrete, and typical asphalt concrete determined worse correlation between binder properties and rutting resistance of SMA mixtures [26]. The influence of the SMA's aggregate gradation that contributes to better stoneto-stone skeleton might be the reason why the binders have lower impact on SMA's rutting resistance. In other words, low performance binder is still able to offer high rutting resistance of SMA asphalt mixtures.

\section{Conclusions}

Obtained results show that, at a higher stress level and temperature, permanent deformation resistance of both control and rubberized asphalt mixtures decreased. However, both rubberized asphalt mixtures (TB and $\mathrm{CB}$ ) are less susceptible 
to temperature compared to control asphalt mixture. For instance, TB and $\mathrm{CB}$ asphalt mixtures tested at high temperature $\left(50^{\circ} \mathrm{C}\right)$ outperform the control asphalt mixture tested at low temperature $\left(40^{\circ} \mathrm{C}\right)$.

Predicted strain values from the Zhou model are similar to measured strain values obtained from the dynamic creep test. It indicates that the creep curve observes the Zhou model trend. Moreover, Zhou's model confirmed that the types of binder blends, rubberized binder, stress levels, and temperatures are significantly influencing the permanent deformation.

Methods to analyse the permanent deformation by dynamic creep curve, total permanent strain, end point at first stage, flow number (FN), and slope of secondary stage are consistent. However, $200 \mathrm{kPa}$ stress level is not sufficiently high enough for evaluation of densification behaviour (first stage) of rubberized asphalt mixtures.

The rubberized binder prepared with terminal blend shows higher viscosity than the continuous blend binder; however the results of the permanent deformation evaluation seem to conclude that the rubberized asphalt mixtures prepared with continuous blend binder present the best performance. It indicates that the correlation between the rubberized binder characteristics and the permanent deformation parameters of asphalt mixtures does not exist.

\section{Competing Interests}

The authors declare that there are no competing interests regarding the publication of this paper.

\section{Acknowledgments}

The authors would like to acknowledge the Department of Civil Engineering, Faculty of Engineering, University of Malaya, Kuala Lumpur, Malaysia, for providing the laboratory facilities to perform this study. This investigation is a part of the research supported by University of Malaya through Grant RP 010A-13SUS.

\section{References}

[1] D. Lo Presti, "Recycled tyre rubber modified bitumens for road asphalt mixtures: a literature review," Construction and Building Materials, vol. 49, pp. 863-881, 2013.

[2] M. Heitzman, "State of the practice-design and construction of asphalt paving materials with crumb rubber," Tech. Rep. FHWA-SA-92-022, Federal Highway Administration ( FHWA), Washington, DC, USA, 1992.

[3] J. Shen and S. Amirkhanian, "Comparison of the properties of laboratory and field prepared CRM binders," in Proceedings of the Asphalt Rubber 2009 Conference, pp. 437-448, Nanjing, China, 2009.

[4] P. Cong, P. Xun, M. Xing, and S. Chen, "Investigation of asphalt binder containing various crumb rubbers and asphalts," Construction and Building Materials, vol. 40, pp. 632-641, 2013.

[5] S.-J. Lee, J. Hu, H. Kim, S. N. Amirkhanian, and K.-D. Jeong, "Aging analysis of rubberized asphalt binders and mixes using gel permeation chromatography," Construction and Building Materials, vol. 25, no. 3, pp. 1485-1490, 2011.

[6] J. R. Willis, P. Turner, C. Plemmons et al., "Effect of rubber characteristics on asphalt binder properties," Road Materials and Pavement Design, vol. 14, supplement 2, pp. 214-230, 2013.

[7] S.-J. Lee, C. K. Akisetty, and S. N. Amirkhanian, "The effect of crumb rubber modifier (CRM) on the performance properties of rubberized binders in HMA pavements," Construction and Building Materials, vol. 22, no. 7, pp. 1368-1376, 2008.

[8] C. K. Akisetty, S.-J. Lee, and S. N. Amirkhanian, "High temperature properties of rubberized binders containing warm asphalt additives," Construction and Building Materials, vol. 23, no. 1, pp. 565-573, 2009.

[9] L. P. T. L. Fontes, G. Trichês, J. C. Pais, and P. A. A. Pereira, "Evaluating permanent deformation in asphalt rubber mixtures," Construction and Building Materials, vol. 24, no. 7, pp. 11931200, 2010.

[10] G. H. Shafabakhsh, M. Sadeghnejad, and Y. Sajed, "Case study of rutting performance of HMA modified with waste rubber powder," Case Studies in Construction Materials, vol. 1, pp. 6976, 2014.

[11] M. Attia and M. Abdelrahman, "Enhancing the performance of crumb rubber-modified binders through varying the interaction conditions," International Journal of Pavement Engineering, vol. 10, no. 6, pp. 423-434, 2009.

[12] A. Khodaii and A. Mehrara, "Evaluation of permanent deformation of unmodified and SBS modified asphalt mixtures using dynamic creep test," Construction and Building Materials, vol. 23, no. 7, pp. 2586-2592, 2009.

[13] A. Mehrara and A. Khodaii, "Evaluation of asphalt mixtures' moisture sensitivity by dynamic creep test," Journal of Materials in Civil Engineering, vol. 23, no. 2, pp. 212-219, 2011.

[14] T. Baghaee Moghaddam, M. Soltani, and M. R. Karim, "Experimental characterization of rutting performance of Polyethylene Terephthalate modified asphalt mixtures under static and dynamic loads," Construction and Building Materials, vol. 65, pp. 487-494, 2014.

[15] Q. Li, F. Ni, L. Gao, Q. Yuan, and Y. Xiao, "Evaluating the rutting resistance of asphalt mixtures using an advanced repeated load permanent deformation test under field conditions," Construction and Building Materials, vol. 61, pp. 241-251, 2014.

[16] ATJ 5/85, "Manual for the structural design of flexible pavement," Jabatan Kerja Raya Malaysia, 2013.

[17] N. S. Mashaan, M. R. Karim, M. Abdel Aziz, M. R. Ibrahim, H. Y. Katman, and S. Koting, "Evaluation of fatigue life of CRMreinforced SMA and its relationship to dynamic stiffness," The Scientific World Journal, vol. 2014, Article ID 968075, 11 pages, 2014.

[18] "Standard specification for road works, Section 4: flexible pavement," Tech. Rep. JKR/SPJ/2008-S4, Jabatan Kerja Raya Malaysia, 2008.

[19] ASTM, "Standard test method for penetration of bituminous materials," ASTM D5/D5M-13.

[20] ASTM, "Standard test method for softening point of bitumen (ring-and-ball apparatus)," ASTM D36/D36M-14e1, ASTM International, West Conshohocken, Pa, USA, 2014.

[21] ASTM, "Standard test methods for rheological properties of non-newtonian materials by rotational viscometer," ASTM D2196-15.

[22] F. J. Navarro, P. Partal, F. Martínez-Boza, and C. Gallegos, "Influence of crumb rubber concentration on the rheological 
behavior of a crumb rubber modified bitumen," Energy \& Fuels, vol. 19, no. 5, pp. 1984-1990, 2005.

[23] D. Lo Presti, "Recycled Tyre Rubber Modified Bitumens for road asphalt mixtures: a literature review," Construction and Building Materials, vol. 49, pp. 863-881, 2013.

[24] R. G. Hicks, D. Cheng, and T. Duffy, "Evaluation of rubberized asphalt terminal blends and a preliminary study on warm mix technologies with asphalt rubber-final summary report," Report CP2C-2010-104, California Pavement Preservation Center, Chico, Calif, USA, 2010, http://www.csuchico.edu/cp2c/ documents/Report/CIWMB-Draft_Final_report_5-14-10.pdf.

[25] T. Baghaee Moghaddam, M. Soltani, and M. R. Karim, "Evaluation of permanent deformation characteristics of unmodified and Polyethylene Terephthalate modified asphalt mixtures using dynamic creep test," Materials \& Design, vol. 53, pp. 317324, 2014.

[26] K. Blazejowski and B. Dolzycki, "Relationships between asphalt mix rutting resistance and MSCR test results," in Design, Analysis, and Asphalt Material Characterization for Road and Airfield Pavements, pp. 202-209, 2014.

[27] S. Dreessen, J. P. Planche, and V. Gardel, "A new performance related test method for rutting prediction: MSCRT," in Advanced Testing and Characterization of Bituminous Materials, vol. 1, pp. 971-980, CRC Press, 2009. 

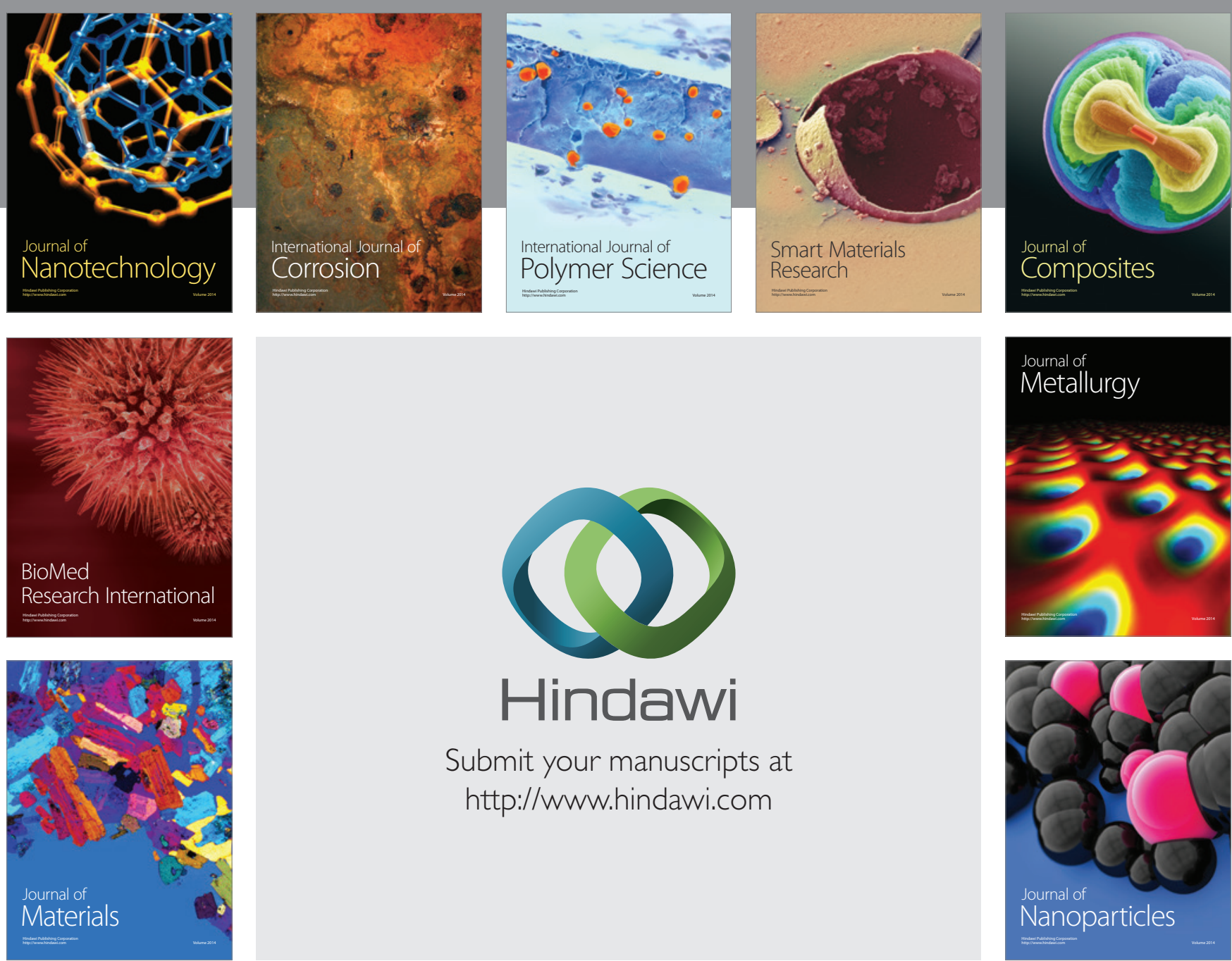

\section{Hindawi}

Submit your manuscripts at

http://www.hindawi.com

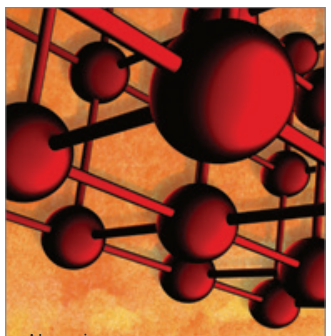

Materials Science and Engineering
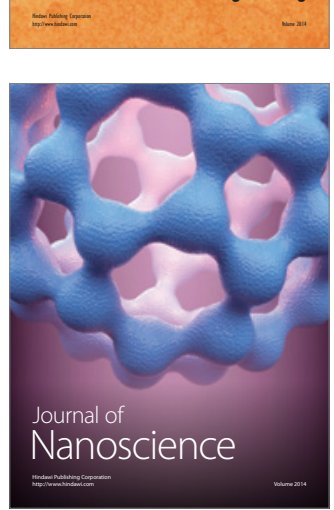
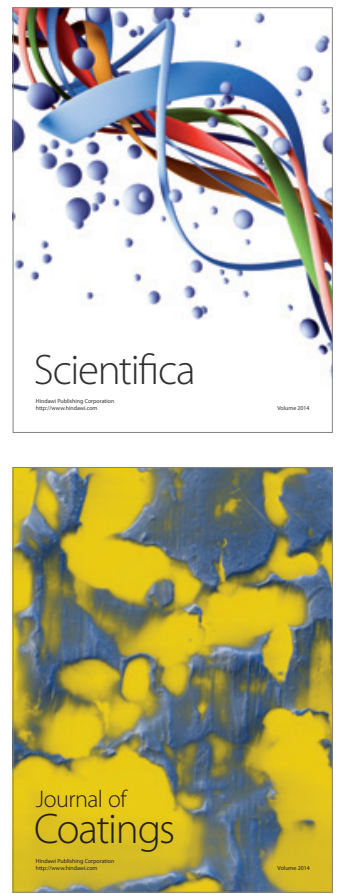
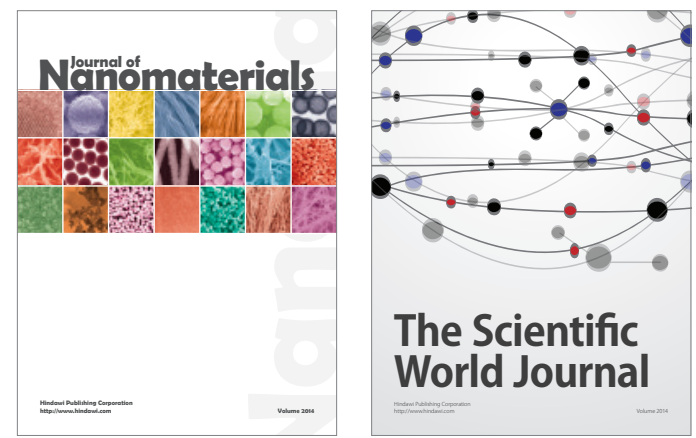

The Scientific World Journal
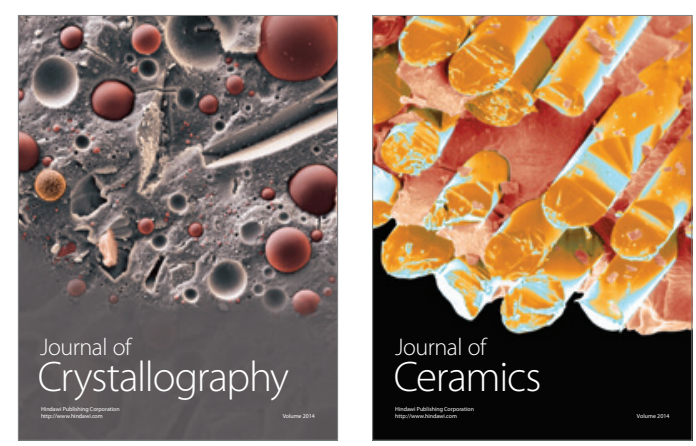
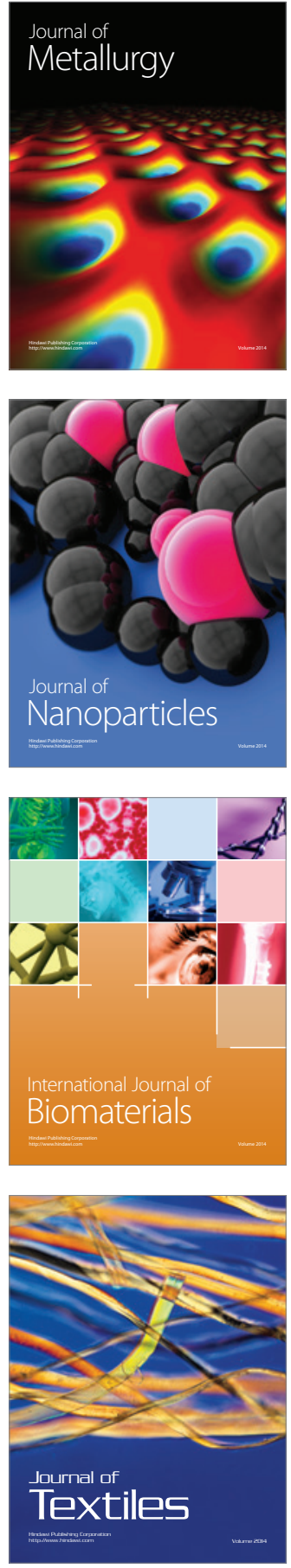